\title{
Impact of percutaneous coronary intervention of chronic total occlusion on left ventricular function using cardiac magnetic resonance imaging
}

Gideon A Paul ${ }^{1 *}$, Kim Connelly², Mo Zia ${ }^{3}$, Alexander J Dick ${ }^{3}$, Brad H Strauss ${ }^{3}$, Graham A Wright ${ }^{4}$

From 2011 SCMR/Euro CMR Joint Scientific Sessions

Nice, France. 3-6 February 2011

\section{Objective}

To assess the role of CMR in the treatment of true chronic total occlusions (CTO) with percutaneous coronary intervention (PCI) and drug eluting stent implantation.

\section{Introduction}

Successful PCI for CTO may confer an improved prognosis and a reduction in major adverse cardiac events. However most trials have included occlusions of short duration (less than 4 weeks). In this study we assessed the impact of PCI on LV function in patients with true CTOs (TIMI flow grade 0 and greater than 12 weeks duration) using serial CMR imaging as well as the pre- dictive value of late gadolinium enhancement when performed prior to revascularization.

\section{Methods}

Thirty patents referred for PCI to a single vessel CTO underwent CMR examination prior to and six months after PCI. Technical success was defined as recanalization of the occluded vessel and DES implantation with a final residual diameter stenosis $<30 \%$. LV function and infarct size were assessed using a 1.5T GE MRI system. Segmental wall thickening (SWT) was measured within the perfusion territory of the CTO using the 16-segment model and segments were dysfunctional if the SWT was $\leq 45 \%$. The transmural extent of infarction (TEI) was

Table 1 Baseline demographics

\begin{tabular}{|c|c|c|c|c|}
\hline & Total $(n=30)$ & CTO-PCI success $(n=19)$ & CTO-PCI failure $(n=11)$ & P-value \\
\hline Age/ years & $62.2 \pm 10.2$ & $62.4 \pm 9.8$ & $61.8 \pm 11.4$ & 0.89 \\
\hline Male,n (\%) & $25(83)$ & $14(74)$ & $11(100)$ & 0.13 \\
\hline CCSA anginal class & $2.13 \pm 0.68$ & $2.21 \pm 0.63$ & $2.0 \pm 0.77$ & 0.42 \\
\hline LVEF/ \% & $53.0 \pm 11.6$ & $50.3 \pm 12.6$ & $57.6 \pm 8.1$ & 0.09 \\
\hline CTO duration, months & $36.9 \pm 70.8$ & $12.6 \pm 26.4$ & $78.8 \pm 101.1$ & 0.01 \\
\hline Vessel, n (\%) & & & & 0.35 \\
\hline RCA & $16(53)$ & $9(47)$ & $7(64)$ & \\
\hline LAD & $11(37)$ & $7(37)$ & $4(36)$ & \\
\hline LCX & $3(10)$ & $3(16)$ & 0 & \\
\hline Prior Ml, n (\%) & $17(59)$ & $11(58)$ & $6(56)$ & 0.61 \\
\hline Diabetes mellitus, n (\%) & $7(23)$ & $5(26)$ & $2(18)$ & 0.61 \\
\hline Hypertension & $23(77)$ & $14(74)$ & $9(82)$ & 0.61 \\
\hline
\end{tabular}

${ }^{1}$ Kings College Hospital, London, UK

Full list of author information is available at the end of the article

(C) 2011 Paul et al; licensee BioMed Central Ltd. This is an open access article distributed under the terms of the Creative Commons 


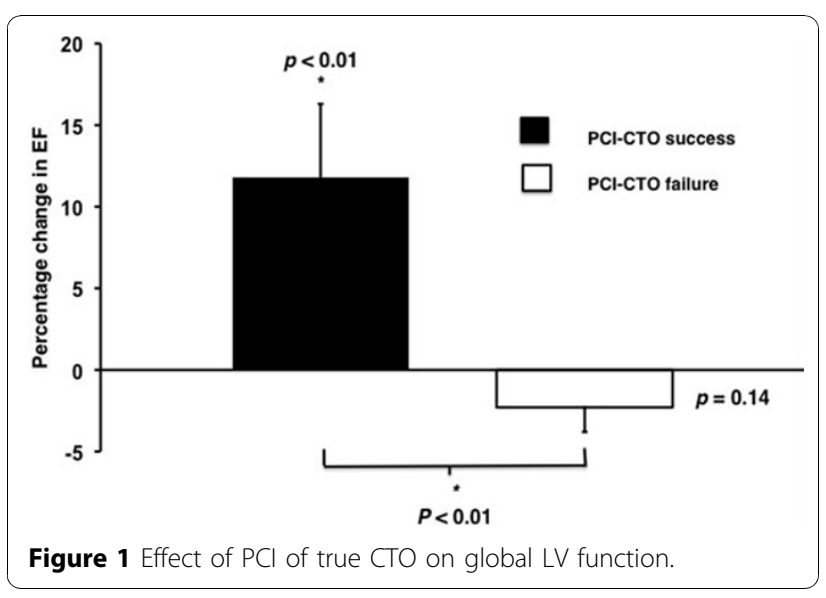

calculated by dividing the hyperenhanced area by the total area $x 100$; a score of $\leq 25 \%$ were considered viable.

\section{Results}

Technical success was achieved in 19 of the 30 patients (63\%). CTO duration was greater in patients with failed revascularization but other baseline demographics were well matched between groups (Table 1). PCI-CTO success resulted in a significant increase in LVEF when compared to both baseline $(50 \pm 13$ vs $54 \pm 11 ; \mathrm{P}<0.01)$ and with PCI-CTO failure $(11.8 \pm 19.8$ vs $-2.3 \pm 5.1, \mathrm{p}<0.01$, Figure 1). In dysfunctional but viable segments only PCI success conferred a significant improvement in SWT compared to baseline ( $26 \pm 6$ vs $40 \pm 10 ; \mathrm{P}<0.001$, Figure 2). There were no episodes of major adverse cardiac events in either group at 21 months follow up.

\section{Conclusion}

PCI-CTO success of true CTOs can improve global LV function. The TEI, assessed with CMR, can be used to help predict improvements in regional wall function.

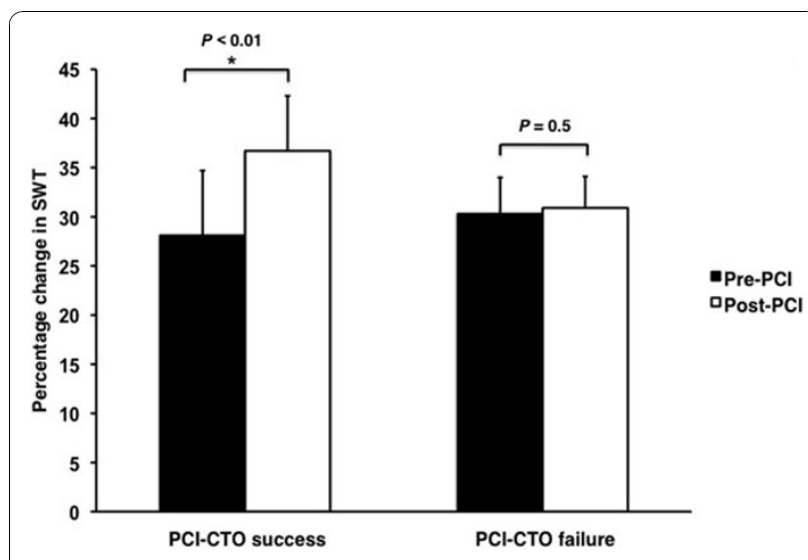

Figure 2 Effect of $\mathrm{PCl}$ on segmental wall thickening in dysfunctional but viable segments.
Failed PCI was not associated with increased MACE at medium-term follow up.

\section{Author details}

${ }^{1}$ Kings College Hospital, London, UK. ${ }^{2}$ St Michaels Hospital, Toronto, ON, Canada. ${ }^{3}$ Sunnybrook Health Sciences Centre, Toronto, ON, Canada.

${ }^{4}$ University of Toronto, Toronto, ON, Canada.

Published: 2 February 2011

doi:10.1186/1532-429X-13-S1-M6

Cite this article as: Paul et al.: Impact of percutaneous coronary intervention of chronic total occlusion on left ventricular function using cardiac magnetic resonance imaging. Journal of Cardiovascular Magnetic Resonance 2011 13(Suppl 1):M6.
Submit your next manuscript to BioMed Central and take full advantage of:

- Convenient online submission

- Thorough peer review

- No space constraints or color figure charges

- Immediate publication on acceptance

- Inclusion in PubMed, CAS, Scopus and Google Scholar

- Research which is freely available for redistribution
Bïmed Central 